Heredity (1973), 30, (2), 227-232

\title{
ATMOSPHERIC POLLUTION AND INDUSTRIAL MELANISM
}

\author{
D. R. LEES, E. R. CREED \\ Department of Zoology, University College of South Wales, Cardiff \\ and \\ J. G. DUCKETT \\ School of Plant Biology, University College of North Wales, Bangor
}

Received 6.v.72

\section{SUMMARY}

\begin{abstract}
The distribution of melanic forms in two moth and two ladybird species has been analysed in relation to fourteen environmental variables by multiple regression. Local smoke levels emerge as important factors in Phigalia pedaria and Adalia bipunctata whereas in Biston betularia sulphur dioxide appears to be the more important. The importance of crypsis is indicated in $P$. pedaria but not in the warningly coloured $A$. bipunctata; nor is it confirmed in $B$. betularia despite earlier experimental results. There is no evidence for industrial melanism in Adalia decempunctata.
\end{abstract}

\section{INTRODUGTION}

AN example of evolutionary change very often quoted in textbooks and elsewhere is the spread of the melanic forms of moths, particularly those of the Peppered Moth, Biston betularia, in Britain since the middle of the nineteenth century; the black coloration of the melanics renders them less liable to predation than the paler typical form when at rest on tree trunks blackened by soot and from which epiphytes are absent (Kettlewell, 1955, 1956; Clarke and Sheppard, 1966; Bishop, 1972). Melanism associated with industrialisation is not confined to species relying on crypsis; it also occurs in the Two-spot Ladybird, Adalia bipunctata (Lusis, 1961; Creed, 1966), which is warningly coloured and distasteful (Frazer and Rothschild, 1960). However, melanic forms of several species which today show industrial melanism also occur in unpolluted areas and have done so since before 1870 (White, 1876). Apart from Edleston's (1864) observations on Biston betularia in Manchester and some data summarised by Barrett (1901) and Doncaster (1906) and later quoted by other authors, information on the time of first occurrence of melanics, and their spread, in industrial areas is very inadequate.

Comparisons of the geographic variation in the frequency of melanics, both between different species of insect and with local environmental conditions, might be expected to indicate some of the factors responsible for maintaining these polymorphisms, and their relative importance in each species, and in particular the part played by the two main air pollutants, smoke and sulphur dioxide. Detailed British distributional data are available for the Peppered Moth (Kettlewell, 1965; Clarke and Sheppard, 1966; Lees, 1971 a), the Pale Brindled Beauty Moth (Lees, 1971b) and the Twospot Ladybird (Creed, 1966, 1971a). We also have some data relating to the Ten-spot Ladybird, Adalia decempunctata, which differs from the other 
three species in that the melanism is genetically recessive (Lus, 1928). In each of the four species more than one melanic form exists but for the purposes of this paper we are combining all melanics into a single class.

\section{Methods}

Measurements of six variables relating to the bark of trees have been made at 104 sites in Britain south of a line running from Preston to York (Creed, Duckett and Lees, in preparation). These parameters were chosen because they provide a measure of local pollution conditions and some affect the crypsis of moths resting on the trees. So that direct comparisons could be made between sites, data were collected from ten mature oak trees in woodland localities which were selected for their environmental similarity. Trees surrounded by dense shrub cover, or in close proximity to water, were excluded. Mean values were obtained for the number of bryophyte species per tree and the maximum height at which they grow, ignoring those in rainwater run-off channels. Four measurements were made on each tree, at a height of $1.5 \mathrm{~m}$., of the log. reflectance and of the proportion of bare bark and that covered by lichens and by algae of the genus Pleurococcus.

Tree species in any one locality differ considerably between themselves in their bark characteristics; however, the trends shown by oaks, when different localities are compared, are reflected to a greater or lesser extent by other species. Our parameters thus provide a relative assessment of local conditions, though not an absolute one, which would depend on the proportions of the various tree species present. In our survey we have had to ignore possible differences in bark characteristics between sessile ( $Q$.petraea), pedunculate ( $Q$.robur) and, occasionally, turkey oaks (Q.cerris) where one species is replaced by another.

Multiple regression analyses were carried out of the melanic frequencies of each species against these parameters of oak trees. In addition we included as independent variables eight physical parameters: National Grid coordinates; height above sea level; mean annual rainfall (Ordnance Survey, 1967); January and July mean temperatures (Meteorological Office, 1952); mean annual atmospheric pollutant levels interpolated from the National Survey (Warren Spring Laboratory, 1964-69) (see table 1). The analysis was carried out using the University of California programme BMD 02R. This first calculates the regression against the variable which has the highest individual correlation with the melanic frequency, and then at each subsequent step adds that variable which gives the greatest increase in $R^{2}$ (the proportion of the variance of the melanic frequencies attributable to the regression). The results of the four series of multiple regressions are summarised in table 1 and the regression equations with the first three independent variables to be included in the analysis of each species are given in table 2.

\section{Discussion}

While there is not necessarily any causal connection between the independent variables with the highest significance and the dependent variable, those parameters which do have a causal connection are likely to appear among the variables with the highest partial regressions. Thus it is perhaps significant that the atmospheric pollutants, either smoke or sulphur dioxide 


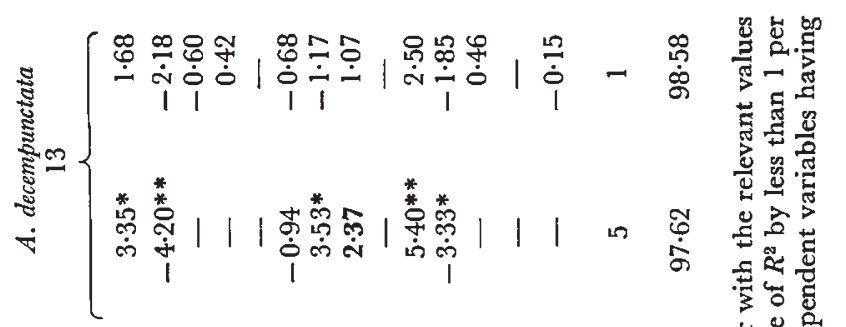

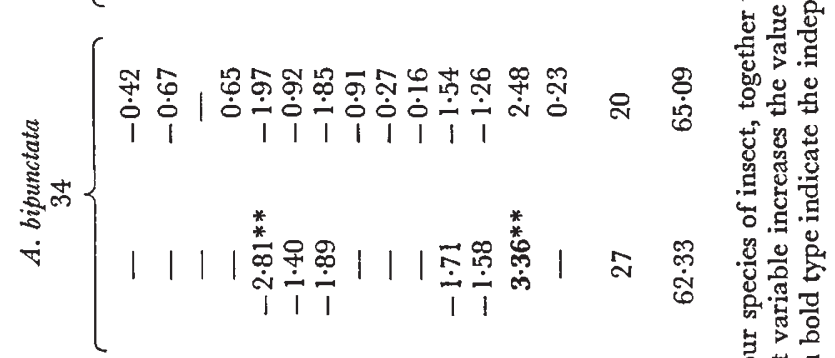

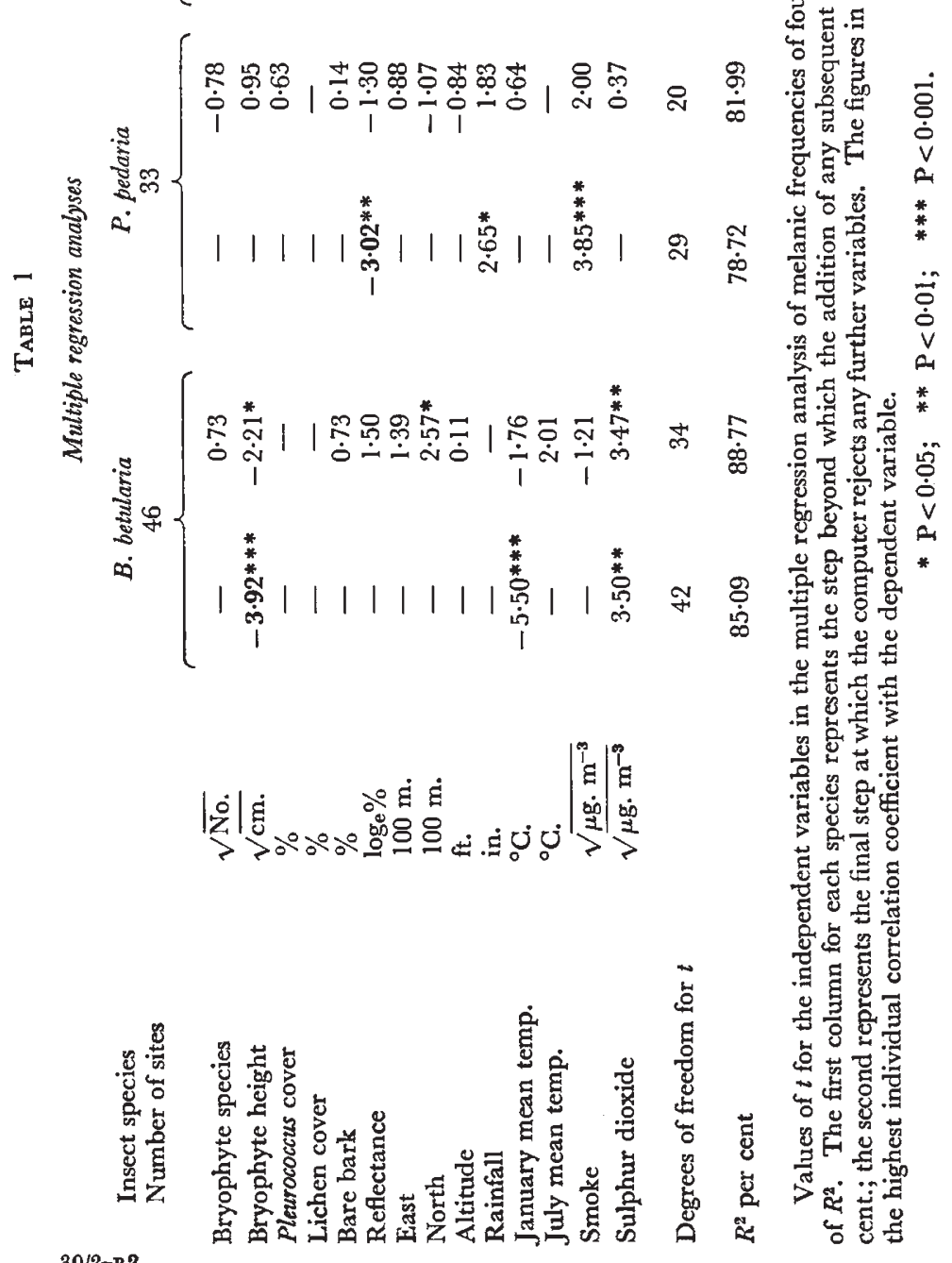


but not both, appear among the first three variables in three of the species, smoke having the highest individual correlation with Two-spot Ladybird melanic frequencies of all the variables included. The correlation coefficient of sulphur dioxide with melanic frequency in Biston betularia is given by $r=0.76$; the correlation with smoke in $P$. pedaria is given by $r=0.81$ and in $A$. bipunctata by $r=0.65$. By comparison with these three species, no clear factors emerge from the analysis of melanic frequencies in $A$. decempunctata; the results provide no real evidence of industrial melanism in this species.

The emergence of reflectance as the most significant single variable in $P$. pedaria seems to confirm that crypsis is important in this species, but its absence, and also that of lichen cover, from the $B$. betularia analysis is surprising in view of the results of Kettlewell's selection experiments (Kettlewell, 1955, 1956). However, it may be that the part of the tree where we measured the reflectance bears little relation to the normal resting place of this species.

TABLE 2

Regression equations
B. betularia
$\%$ melanic $=644 \cdot 1-14 \cdot 87 \mathrm{Jan}$. Temp. $-2 \cdot 40 \sqrt{\mathrm{Bryo} . \mathrm{Ht}} .+4 \cdot 23 \sqrt{\mathrm{SO}_{2}}$
$P$. pedaria
$\%$ melanic $=74.4+6 \cdot 14 \sqrt{\text { Smoke }}-34.56$ Reflectance +0.41 Rainfall
A. bipunctata
$\%$ melanic $=-4.3+11 \cdot 25 \sqrt{\text { Smoke }}-0.008$ East -0.31 Bare bark
A. decempunctata
$\%$ melanic $=27 \cdot 8+0.006$ North -0.004 East +0.62 Rainfall

Regression equations for the percentage frequency of melanic individuals in four species of insect against the first three variables included in the regression analysis. The units of measurement are the same as in table 1 .

In spite of this possible objection, it is certainly true that high melanic frequencies of $B$. betularia, but not of $P$. pedaria, are found in East Anglia where the trees are light in colour. Bishop (1972.) has also suggested from his experimental, distributional and computer simulation studies that a selective factor in addition to predation by birds has a major effect on melanic frequencies of $B$. betularia. Reflectance was entered as the sixth variable in $A$. bipunctata, implying that crypsis is of little importance in this aposematic species, which anyway is often encountered against the green background of a leaf. Mean annual rainfall is the third variable to be entered against $P$. pedaria; it has, however, an individual correlation, $r$, of only 0.11 which suggests that this variable, or a further one in turn correlated with it, is having a small but important influence. It is most unlikely that the mean maximum height at which bryophytes grow can have a direct effect on melanic frequencies in $B$. betularia; again it seems that some additional, correlated factor has not been identified. Similar difficulties are encountered in interpreting the importance of mean January and July temperatures, though a differential viability response may be involved. In $B$. betularia the significance of mean January temperature drops dramatically when distance East is included in the regression, but this does not remove the possibility that the pupae of melanic $B$. betularia may be better able to survive cold winter conditions than the non-melanics.

The decrease in melanic frequencies of $A$. bipunctata in Birmingham following the introduction of smoke control zones provides further evidence that smoke is the most important selective factor in the melanic polymorphism of this species (Creed, 1971b). Decreases in the melanic frequency 
of $B$. betularia have also been reported in areas subject to the control of smoke emissions (Clarke and Sheppard, 1966; Askew, Cook and Bishop, 1971). It is tempting to suggest that the smaller frequency changes observed, than in $A$. bipunctata, may result from the smaller decrease in sulphur dioxide levels compared with smoke. However, the initial frequencies of the melanic moths were much higher, and consequently the same changes in the forces of natural selection would lead to a smaller initial change in gene frequency. Our analysis leads us to predict that, with the present day changes in smoke levels and the reflectance of polluted surfaces, the frequency of melanic $P$. pedaria in urban areas should show decreases of the same order of magnitude as those observed in $A$. bipunctata. Such has been the tendency of entomologists to collect series of specimens and not random samples that we do not have the necessary data relating to earlier years to check this prediction at the present time.

Acknowledgments.-We thank Professor E. B. Ford, F.R.S., Dr H. B. D. Kettlewell and Professor P. M. Sheppard, F.R.S., for their comments on this paper. Part of the work was supported by a Royal Society Government Grant.

\section{REFERENGES}

ASKEW, R. R., COOK, L. M., AND BISHOP, J. A. 1971. Atmospheric pollution and melanic moths in Manchester and its environs. 7. appl. Ecol., 8, 247-256.

BARRETT, c. G. 1901. The Lepidoptera of the British Islands, Vol. 7. Lovell Reeve, London. BISHOP, J. A. 1972. An experimental study of the cline of industrial melanism in Biston betularia (L.) (Lepidoptera) between urban Liverpool and rural North Wales. 7. Anim. Ecol., 41, 209-243.

CLARKE, C. A., AND SHEPPARD, P. M. 1966. A local survey of the distribution of industrial melanic forms of the moth Biston betularia and estimates of the selective value of these in an industrial environment. Proc. $R$. Soc., B, 165, 424-439.

CREED, E. R. 1966. Geographic variation in the Two-spot Ladybird in England and Wales. Heredity, 21, 57-72.

GREED, E. R. 1971a. Melanism in the Two-spot Ladybird, Adalia bipunctata, in Great Britain. In Ecological Genetics and Evolution (edit. by Creed, E. R.), pp. 134-151. Blackwell, Oxford.

GREED, E. R. 1971 b. Industrial melanism in the Two-spot Ladybird and smoke abatement. Evolution, 25, 290-293.

DONCASTER, L. 1906. Collective enquiry as to progressive melanism in Lepidoptera. Entomologist's Rec. J. Var., 18, 165-168, 206-208, 222-226, 248-254.

EDLEston, R. s. 1864. Amphydasis betularia. Entomologist, 2, 150.

FRAZER, J. F. D., AND ROTHSCHILD, THE HON. M. 1960. Defence mechanisms in warningly coloured moths and other insects. Proc. 11th Cong. Entomology, 3, 249-256.

KETTLEWELL, H. B. D. 1955. Selection experiments on industrial melanism in the Lepidoptera. Heredity, 9, 323-342.

KETTLEWELL, H. B. D. 1956. Further selection experiments on industrial melanism in the Lepidoptera. Heredity, 10, 287-301.

KETTLEWELL, H. B. D. 1965. A twelve year survey of the frequencies of Biston betularia (L.) (Lep.) and its melanic forms in Great Britain. Entomologist's Rec. 7. Var. 77, 195-218.

LEEs, D. R. 1971 a. A study of some factors affecting the geographic distribution of melanism in moths. D.Phil. Thesis, Bodleian Library, Oxford.

LEEs, D. R. $1971 b$. The distribution of melanism in the Pale Brindled Beauty Moth, Phigalia pedaria, in Great Britain. In Ecological Genetics and Evolution (edit. by Creed, E. R.), pp. 152-174. Blackwell, Oxford.

Lus, J. J. 1928. On the inheritance of colour and pattern in ladybeetles Adalia bipunctata L. and Adalia decempunctata L. Izv. Byuro Genet. Leningrad, 6, 89-163.

Lusis, J. J. 1961. On the biological meaning of colour polymorphism of ladybeetle Adalia bipunctata L. Latvijas Entomologs, 4, 3-29. 
METEOROLOGical OfFice. 1952. Climatological Atlas of the British Isles. Her Majesty's Stationery Office. London.

ORdNANCE SURVey. 1967. Average Annual Rainfall, 1915-50. "Ten Mile" Map of Great Britain, South $(1 / 625000)$.

WARREN SPRING LABORATORY. 1964-69. The Investigation of Air Pollution. Annual Summaries.

WHITE, D. F. B. 1876. On melanochroism and leucochroism. Entomologist's mon. Mag., 13, 145-149. 